\title{
Using Electron-Probe Microanalysis and Quantitative Compositional Mapping to Study Lithic Clasts in Lunar Meteorites NWA 2727 and NWA 3170
}

\author{
S.N. North-Valencia ${ }^{1}$, P.K. Carpenter ${ }^{1}$, B.L. Jolliff ${ }^{1}$, R.L. Korotev ${ }^{1}$ \\ ${ }^{1}$ Washington University in St. Louis, Department of Earth and Planetary Sciences and the McDonnell \\ Center for the Space Sciences, St. Louis USA
}

Northwest Africa (NWA) 2727 and NWA 3170, two different stones of the same lunar meteorite, are mineralogically and chemically similar [1,2]. Both are breccias that contain an apparently related suite of lithic and mineral clasts. To investigate petrogenetic relationships, we have determined mineral compositional zoning characteristics with Electron Probe Microanalysis (EPMA). The mineralogy includes alkali feldspar (K, Ba, Na), plagioclase, pyroxene (zoned $\mathrm{Mg}-\mathrm{Fe}-\mathrm{Ca}$ ), olivine (Fe-rich), and minor amounts of Fe-Ti oxides, phosphates, and troilite. Alteration (Ca-carbonate fracture fillings) occurs in both meteorites, resulting from hot-desert weathering. In the lithic clasts, mineral-chemical zoning trends, e.g., in pyroxene, are especially useful for comparing lithic clasts and constraining their origins. We used quantitative compositional mapping to study compositional variations, especially for pyroxenes as diagnostic of petrogenetic relationships. We find that quantitative compositional maps extend the characterization of mineral-chemical trends beyond that obtained by EPMA spot analyses.

Chemical and textural characterization of NWA 2727 and NWA 3170 minerals and lithic clasts were done using backscattered-electron (BSE) imaging, EPMA and WDS quantitative stage mapping of polished samples with a JEOL JXA-8200 electron microprobe. According to the methods of [3], $512 \times$ 512 pixel maps were collected at $50 \mathrm{nA}$ with count times of 20 to $50 \mathrm{msec}$, step sizes of 1 to $10 \mu \mathrm{m}$, and spot sizes set to match the step size. A conventional WDS calibration was done using Probe for EPMA (Probe Software), allowing direct comparison of compositional data from quantitative compositional maps with data from spot analyses. WDS background subtraction was made using the calibrated mean atomic number (MAN) method. A full $\Phi(\rho z)$ correction, relative to a set of standards, was calculated at each pixel using Calclmage and the resulting data sets were visualized using Surfer (Golden Software).

Ferroan gabbro lithic clasts in both NWA 2727 and NWA 3170 show significant Mg-Fe zoning. Quantitative compositional maps of NWA 3170 allow us to examine this zoning, by providing the wt. \% of mapped elements at each pixel (Fig. 1). Results of the quantitative compositional maps are corroborated by spot analysis. Spot analysis shows that pyroxene compositions-range from $\mathrm{Wo}_{14} \mathrm{En}_{46} \mathrm{Fs}_{40}$ to $\mathrm{Wo}_{36} \mathrm{En}_{5} \mathrm{Fs}_{59}$. The full extent of chemical zoning of pyroxene in the $\mathrm{FG}$, however, is more fully determined using the quantitative compositional data obtained through mapping. Figure 2 compares data obtained by spot analysis with data extracted from quantitative compositional mapping. The data obtained by quantitative compositional mapping reveals a broader distribution of pyroxene compositions provides key information about the composition and evolution of melt that crystallized to form this assemblage. In this case, pyroxene compositions evolved to the Fe-rich side of the quadrilateral, resulting in the formation of symplectites, likely resulting from breakdown of pyroxferroite and crystallization of quartz, fayalite, and hedenbergite. A late-stage trend toward hedenbergite is indicated (Fig. 2). 
Quantitative compositional mapping can also be used to calculate the bulk composition of lithic clasts. For example, in NWA 2727, one clast contains a eutectoid intergrowth of silica, pyroxene, olivine, plagioclase, and ilmenite, with trace troilite. Bulk composition determined by modal recombination (using phase area fraction combined with spot analysis, with density correction) provides similar results to bulk composition determined from quantitative compositional mapping. Calculating the bulk composition of lithic clasts includes a density correction (using CalcImage), which is especially important where phases have a large density contrast. Mineral compositions provide evidence for lithic clast pairings as well as possible petrogenetic relationships. Quantitative compositional mapping provides an improved understanding of compositional variation in these lithic clasts, and an improved basis for comparison between lithic clasts in the two different lunar samples.

\section{References:}

[1] Meteoritical Bulletin 101 (2013).

[2] H C Connolly et al, Meteoritical Bulletin 90 (2006).

[3] P C Carpenter et al, LPSC 40, Abstract \#1827 (2013).

[4] This work was funded by NASA Cosmochemistry grant NNX11AJ66G (RLK).

NWA 3170 Ferroan Gabbro

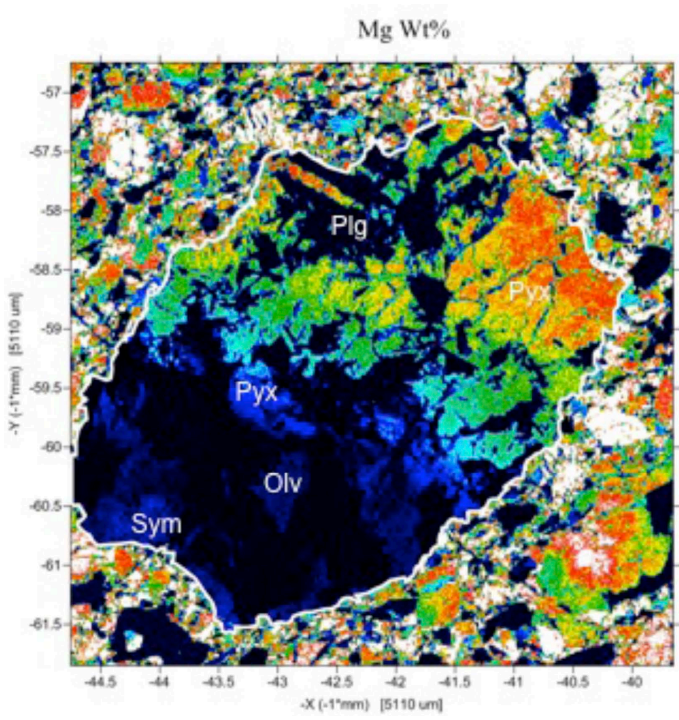

NWA 3170 Ferroan Gabbro $\mathrm{Fe} \mathrm{Wt} \%$
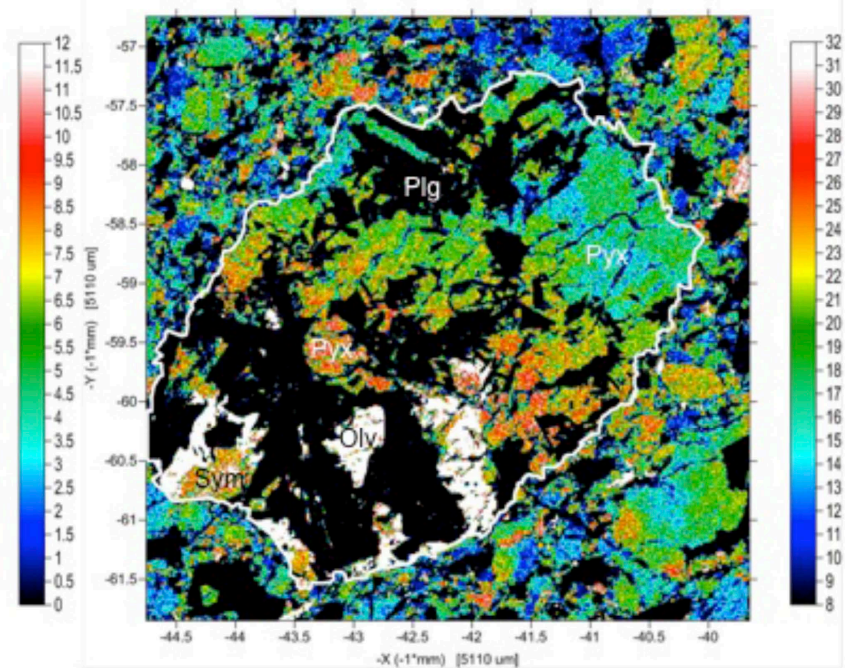

Figure 1. Quantitative Compositional Maps of a FG clast, outlined in white, and surrounding breccia in NWA 3170. Plg = plagioclase, $\mathrm{Pyx}=$ pyroxene, $\mathrm{Olv}=$ olivine, and $\mathrm{Sym}=$ symplectite .
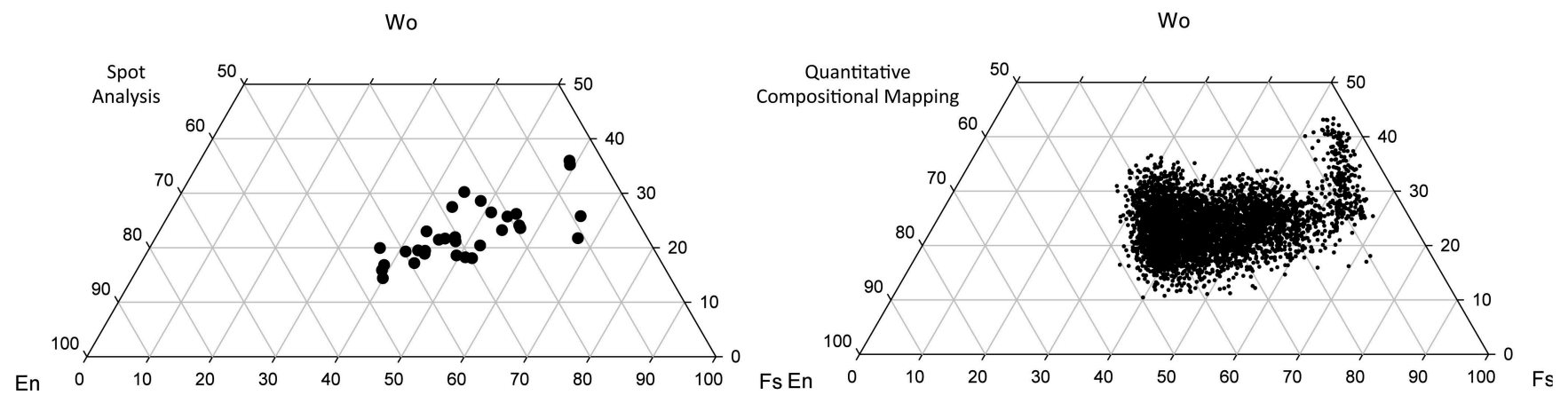

Figure 2. Compositions of pyroxene in a FG clast in NWA 3170 in terms of end member compositions. 